\title{
Protective Efficacy of Solanum Hainanense Hance during Hepatotoxicity in Male Mice with Prolonged and Small Oral Doses of Trinitrotoluene
}

\author{
Nguyen Phuc Thar ${ }^{1}$, Le Van Trung ${ }^{2}$, Nguyen Khac $\mathrm{HaI}^{3}$ and Le HuYnh ${ }^{3}$ \\ 'Department of Occupational Health, Military Institute of Hygiene and Epidemiology, \\ ${ }^{2}$ National Institute of Occupational and Environmental Health and \\ ${ }^{3}$ Military School of Medicine
}

\begin{abstract}
Protective efficacy of Solanum Hainanense Hance During Hepatotoxicity in Male Mice with Prolonged and Small Oral Doses of Trinitrotoluene: Nguyen Phuc THAl, et al. Department of Occupational Health, Military Institute of Hygiene and Epidemiology-A cluster of patients with anemia, aplasia, methemoglobinemia and hepatotoxicity were found among workers in explosive material factories in Vietnam. Trinitrotoluene (TNT) was suspected of causing the disorders. This study aims to evaluate the use of Solanum hainanense Hance for liver protection of white mice which were poisoned with prolonged and small oral doses of TNT. Thirty-six mice were assigned equally to 3 groups: control group, poisoned group and protected group. The poisoned group received a TNT oral dose of $100 \mathrm{mg} / \mathrm{kg}$ body weight daily 6 times weekly for $6 \mathrm{wk}$, and the protected group were administered a Solanum hainanense hance solution dose of $6 \mathrm{~g} / \mathrm{kg}$ body weight daily $4 \mathrm{~h}$ before receiving the same dose as the poisoned group. They were followed up for $6 \mathrm{wk}$. Body and liver weights were measured, tissues were histopathologically examined and laboratory tests (glucose, MetHb, -SH concentrations and serum AST, ALT) were done at the end of the experiment. The results were as follows: Serum AST and ALT activities were significantly different in the three groups (Control group: $280 \pm 107$ and $55.2 \pm 22.5$ U//; Poisoned group: $486 \pm$ 267 and $102.8 \pm 44.9$ U//; Protected group: $288 \pm 164$ and $78.3 \pm 9.6 \mathrm{U} / \mathrm{I}$ ). MetHb, glucose and $-\mathrm{SH}$ concentrations were changed by TNT, and these changes were increased in the Solanum hainanense hance-protected group but the increase was not statistically significant. The cut off point at $1483 \mathrm{mg}$ and ratios of hepatomegaly were significantly different in the
\end{abstract}

Received November 11, 1997; Accepted July 6, 1998

Correspondence to: Nguyen Phuc That, Depariment of Occupational Health, Military Institute of Hygiene and Epidemiology, I85 pho

Nguyen Luong Bang, Dong da, IIa noi, Viet nam three groups (Control group: 1/12; Poisoned group: $10 /$ 12; Protected group: $6 / 12$ ). The cut off point at $58.7 \%$ and ratios of increase in density of the liver and of body weights were significantly different in the three groups (Control group: 1/12; Poisoned group; 6/12; Protected group 3: 1/12). Histological examination of the livers showed normal histological features in control mice, histopathological lesions in TNT-poisoned mice and the alleviation of TNT-induced lesions in protected mice. TNT has caused histopathological lesions and changed liver function tests. These lesions and changes in biochemical tests could be significantly restricted by Solanum hainanense Hance solution. The results suggest that Solanum hainanense hance could protect against TNT-induced liver damage.

(J Occup Health 1998; 40: 276-278)

Key words: Trinitrotoluene, TNT, Mice, Liver, Hepatotoxicity, Solanum hainanense hance

A cluster of patients with anemia, aplasia, methemoglobinemia and hepatotoxicity were found among workers in explosive material factories in Vietnam"). The liver is frequently at risk from TNT exposure in humans and animals ${ }^{2,3)}$. TNT causes hepatocellular injury, which may lead to chronic liver dysfunction and cirrhosis in cases of prolonged exposure. In Vietnam, the prevalence of poison-related hepatitis in workers with prolonged exposure to TNT was very high; it was found to be $15.23 \%$ ". Reports of hepatic failure caused by TNT have led investigators to consider that there is a need try to look for a remedy that can prevent that damage. In Vietnam, a traditional remedy Solanum hainanense hance, grown and found in many areas, has been used in anti-inflammation, anti-histaminemia, and vernomous snake, bite treatment namely. The Vietnam Institute of Pharmaceutical Material confirmed that Solanum hainanense hance contains proline, hydroxyproline, methionin, flavonoid and saponin 
steroid ${ }^{5}$. Recently, it has been reported to be effective in preventing experimental inflammation and cirrhosis in sewer rats poisoned by $\mathrm{CCl}_{4}^{6,7}$. Our study is the first step in evaluating the use of Solanum hainanense hance for liver protection of white mice which were poisoned with prolonged and small oral doses of TNT, and further investigation on a protective role of Solanum hainanense hance in poisonrelated hepatitis in workers exposed to TNT.

\section{Materials and Methods}

\section{Chemicals}

Solution 1 is sesame oil, Solution 2 is composed of industrial TNT obtained from Explosive Factory No. 131, dissolved completely in sesame oil at a concentration of $10 \mathrm{mg} / \mathrm{m} l$, and Solution 3 is composed of Solanum hainanense hance solution at a concentration of $1 \mathrm{~g} / \mathrm{ml}$, and this solution was prepared by the Vietnam Institute of Pharmaceutical Material.

\section{Animal}

Thirty-six male white mice $(17.5 \pm 0.5 \mathrm{~g})$ were obtained from the Department of Laboratory Animal Supply, Military School of Medicine. The mice were housed in three steel chambers, provided with food and water, and maintained under the following conditions: light 12-hrs/ $12 \mathrm{hrs}$, dark/light cycle and temperature $24-28^{\circ} \mathrm{C}$.

\section{Animal treatment}

Thirty-six male white mice were assigned equally to 3 groups: the control group (Group 1) receiving Solution 1 at a dose of $10 \mathrm{~m} l / \mathrm{kg}$ body weight daily 6 times weekly for $6 \mathrm{wk}$, the poisoned group (Group 2) receiving Solution 2 at a dose of $10 \mathrm{~m} l(100 \mathrm{mg}) / \mathrm{kg}$ body weight daily 6 times weekly for $6 \mathrm{wk}$, and the protected group (Group $3)$ treated with Solution 3 at a dose of $6 \mathrm{ml}(6 \mathrm{~g}) / \mathrm{kg}$ body weight daily $4 \mathrm{hr}$ before receiving the same dose as Group 2. Blunt needles were used for mouse poisoning and feeding.

\section{Details of Examinations}

All 36 mice were killed after $6 \mathrm{wk}$ to do laboratory tests activities of serum aspartate aminotransferase (AST), alanine aminotransferase (ALT), glucose, methemoglobin $(\mathrm{MetHb})$ and plasma -SH concentration], and measure body and liver weights. Histological sections of tissue obtained at autopsy were stained with hematoxylin-eosin and examined under a light microscope. Histopathological changes in the liver were graded according to the degree of hepatocellular degeneration, periportal necrosis, and portal and lobular inflammation.

\section{Data analysis}

Laboratory tests, body and liver weights and density of the liver and body weights are expressed as the mean \pm SD. The differences between laboratory tests, body and liver weights, and density of the liver and body weights of poisoned, protected and control groups were analyzed by paired Student's $t$-test and Chi square test. Results were considered statistically significant at a pvalue less than 0.05 .

\section{Results}

\section{Laboratory tests}

The results of laboratory tests (Table 1) showed that TNT produced a significant increase in serum AST and ALT activities. The actions were marginally higher in the Solanum hainanense hance protected group than in the TNT poisoned control group ( $\mathrm{p}<0.05)$; glucose and SH concentrations in group 2 tended to decrease in comparison with group 1 and the decrease was limited by the efficacy of Solanum hainanense hance solution in Group 3, but the changes were not statistically significant. MetHb concentrations were higher in both Groups 2 and 3 than in Group 1 but not significantly.

\section{Liver weight}

The body and liver weights and density of the liver and body weights of animals (Table 2) showed that TNT produced a significant increase in the incidence of hepatomegaly. The increase was limited by the efficacy of Solanum hainanense hance solution in Group 3.

\section{Histopathological features}

A total of 36 mice underwent a histological examination of the liver, which showed normal histological features in control mice. In contrast, in the poisoned group the 
Table 2. Effects of Solanum hainanense hance on TNT-induced changes in body and liver weights

\begin{tabular}{|c|c|c|c|c|c|c|c|}
\hline \multirow{2}{*}{ Groups } & \multirow{2}{*}{$\frac{\text { Body weight }(\mathrm{g})}{\text { mean } \pm \mathrm{SD}}$} & \multicolumn{3}{|c|}{ Liver weight (mg) } & \multicolumn{3}{|c|}{ liver weight/body weight (\%c) } \\
\hline & & mean $\pm \mathrm{SD}$ & $\leq 1483$ & $>1483$ & mean $\pm \mathrm{SD}$ & $\leq 58.7$ & $>58.7$ \\
\hline Control $(n=12)$ & $27.2 \pm 3.7$ & $1309 \pm 174$ & 11 & 1 & $51.8 \pm 6.9$ & 11 & 1 \\
\hline Poisoned $(n=12)$ & $27.6 \pm 2.9$ & $1549 \pm 179$ & 2 & $10^{*}$ & $56.5 \pm 5.1$ & 6 & $6^{*}$ \\
\hline Protected $(n=12)$ & $28.0 \pm 3.1$ & $1470 \pm 192$ & 6 & $6 * *$ & $54.4 \pm 4.4$ & 11 & $1 * *$ \\
\hline
\end{tabular}

*p<0.05 compared to control group as evaluated by Chi square test (cut off point at $1483 \mathrm{mg}$ ). **p<0.05 compared to poisoned group as evaluated by Chi square test (cut off point at $1483 \mathrm{mg}$ ).

liver cells showed various stages of degenerative processes (hydropic change with large clusters of hepatocytes and fatty change), there was evidence of bile retention, total loss of hepatic parenchyma including necrotic liver cells, encircling of these necrotic areas by mononuclear and polymorphonuclear cells, a patchy chronic inflammatory infiltration including lymphocytes, regenerated hepatic cells and haemorrhage scattered over the liver parenchyma, dilated central vein and sinusoidal congestion. There was a different degree of liver damage in the protected group to that in the poisoned group; The histopathological findings had less lesions at presentation than in poisoned mice, and it has been demonstrated that in protected mice mild changes occur: hepatocellular degeneration, characterized by cloudy swelling, hydropic degeneration and small necrosis with inflammatory infiltration. Fatty deposit, haemorrhagic parenchyma and loss of hepatolobular structure were not seen in this group. This may be due to the effect of Solanum hainanense hance in addition to TNT-induced hepatotoxicity.

\section{Discussion}

The protective effect of Solanum hainanense hance on TNT-induced liver damage depends on interactions between TNT and its metabolists and the composition of Solanum hainanense hance and between Solanum hainanense hance and liver cells. On entering the body, TNT is metabolized in liver cells and enhances formation of superoxide radical and hydrogen peroxide ${ }^{8)}$, which attack the lipoprotein structure of hepatocellular biomembranes by lipoperoxide chain reaction inducing hepatocellular necrosis. Bio-flavonoid, which is known as an anti-oxidative agent ${ }^{9)}$, in Solanum hainanense hance can restrict the lipoperoxide chain reaction caused by oxidative agents, the formation of which is enhanced by TNT metabolism in liver cells. The saponin steroids in Solanum hainanense hance have been shown to increase the tolerance of the membrane of liver cells under attack by TNT, its metabolites and oxidative agents. Solanum hainanense hance has been reported to reduce $\mathrm{CCl}_{4}^{-}$ induced liver damage in laboratory animals $\mathrm{s}^{61}$, similar to the reduction of TNT-induced liver damage in our study. In this first step, the results suggest that Solanum hainanense hance may alleviate TNT-induced liver damage. In the near future, therefore, we are going to try to seek more evidence of the protective effect of Solanum hainanense hance in a more perfect study.

In conclusion, it was found in the present study that TNT causes many histopathological lesions in the liver and changes in liver function tests in white mice. The results of our study strongly suggest that Solanum hainanense hance could protect against TNT-induced liver damage in laboratory animals.

\section{References}

1) Trung LV. Occupational toxicity of trinitrotoluene (TNT). In: Trung LV, ed. Occupational diseases. Hanoi: Publishing House of Medicine, 1994: 258-263 (in Vietnamese).

2) Levine BS, Furedi EM, Gordon DE, Lish PM, Barkley JJ. Sub-chronic toxicity of trinitrotoluene in Fischer 344 rats. Toxicology 1984; 32: 253-265.

3) Arena JM. Trinitrotoluene. Poisoning: ToxicologySymptoms-Treatment. Charles C Thomas Publisher, 1986: 206-207.

4) Lieu N. Study on toxicity of trinitrotoluene in workers exposed to it in prolongation. The Ph.D. thesis. Hanoi: Military School of Medicine, 1996 (in Vietnamese).

5) Man PK. Solanum hainanense Hance. In: Man P.K., Bich D.H., Dam D.T. Vietnamese medicinal plant. Hanoi: Technological and Scientific Publishing House, 1990: 370-71 (in Vietnamese).

6) Khai NM. Study on effect of Solanum hainanense Hance and LH 1 in experimental cirrhosis. In: Annals of scientific work of pharmacy and medicine. Hanoi: Vietnam Institute of Pharmaceutical Material, 1988: 31-35 (in Vietnamese).

7) Khai NM. Study on effect of chemicals and pharmaceutical products in collagenase collagen and its possibilities in treatment. The Ph.D. thesis. Hanoi: College of Pharmacy, 1991 (in Vietnamese).

8) Kong LY, Jiang QG, Qu QS. Formation of superoxide radical and hydrogen peroxide enhanced by trinitrotoluene in rat liver, brain, kidney, and testicle in vitro and monkey liver in vivo. Biomed Environ Sci 1989; 2: 72-77.

9) Bao DT. Anti-oxidative agents in biology, medicine and pharmacy. J. Pharm. 1985; 1: 21-28 (in Vietnamese). 